\title{
Evaluation of indirect loss from hypothetical catastrophes in two regions with different economic development levels in China
}

\author{
W. Xie ${ }^{1,3}$, N. Li ${ }^{1,2,3}$, J.-D. Wu ${ }^{1,2,3}$, and X.-Q. Liu ${ }^{1,3}$ \\ ${ }^{1}$ State Key Laboratory of Earth Surface Processes and Resource Ecology (Beijing Normal University), Beijing 100875, China \\ ${ }^{2}$ Key Laboratory of Environmental Change and Natural Disaster (Beijing Normal University), Ministry of Education, \\ Beijing 100875, China \\ ${ }^{3}$ Academy of Disaster Reduction and Emergency Management, Ministry of Civil Affairs \& Ministry of Education, \\ Beijing Normal University, Beijing 100875, China
}

Correspondence to: N. Li (ningli@bnu.edu.cn)

Received: 29 November 2011 - Revised: 26 August 2012 - Accepted: 17 October 2012 - Published: 14 November 2012

\begin{abstract}
This study evaluates and compares the indirect economic loss (IEL) resulting from two hypothetical catastrophes occurring in China - in developed Shanghai and in less-developed Sichuan - to provide new measures of disaster reduction. IEL was divided into indirect economic loss due to the disruption of production process (IEL I) and indirect economic loss induced by the disturbance of industrial lines (IEL II). An input-output model was used to assess these two types of IEL. The study showed that (1) developed regions may be more vulnerable with respect to IEL; (2) IEL II is the primary factor contributing to total IEL; (3) decision makers need to focus on IEL II beside IEL I which is usually the main disaster-reduction target after a disaster; and (4) tradeoff between economic growth and disaster prevention is needed to achieve regional sustainable development.
\end{abstract}

\section{Introduction}

In the context of global change, natural hazards are increasing in intensity, frequency, impacted area and duration (ISDR, 2008; IPCC, 2012). The hurricane Katrina in 2005 (USA), the Wenchuan Earthquake in 2008 (China), the Great East Japan Earthquake in 2011 (Japan) and other global large-scale disasters have caused heavy casualties and expensive property loss. To improve the ability of disaster risk management and accelerate the speed of recovery and reconstruction, the loss assessment of natural hazards has become a topic of intense research in the arena of sustainable development (e.g. Tierney, 1997; Benson and Clay, 1998, 2004; Pelling, 2002; Rasmussen, 2004; Raschky, 2008; Wu et al., 2012; Xie et al., 2012). Losses of disasters can often be classified into 2 categories: direct loss (e.g. damaged residences, destroyed infrastructures, loss of life) and indirect loss (e.g. business interruption, production losses, supplydemand mismatch). These two types of losses can be further divided into tangible and intangible losses, according to whether they are traded in a market and can be easily expressed in monetary terms (FEMA, 2001; ECLAC, 2003; Bubeck and Kreibich, 2011; IPCC, 2012).

After every large-scale disaster, government institutions, insurance markets, and the media have primarily focused on the resulting direct losses. However, the total impact of a disaster cannot be expressed solely in terms of direct economic loss. An obvious illustration is that when infrastructure sectors such as electric power or transportation systems are destroyed, the impact of disasters may be transferred to other sectors within the economic system along the supply chain. The regional economic growth may be further affected with the rapidly developing societies and the closer links among industrial sectors. For example, electricity transmission lines were destroyed by the 2008 Wenchuan earthquake in China, causing operation termination in industry outside the hazard area, putting people out of work, and creating some other problems. Therefore, indirect loss assessment of natural hazards is helpful to governments that have an interest in the total and precise impact of disasters in the period of recovery and reconstruction. And it must be included in the total loss to ensure an efficient disaster reduction planning. In 
China, disaster prevention and economic development are planned once every $5 \mathrm{yr}$. These plans are supposed to take indirect loss of disasters into account to ensure a fair costbenefit analysis of the protection measures for infrastructures or other mitigating actions. Additionally, post-disaster direct economic losses are already in existence once a disaster strikes and cannot be reduced, while indirect economic losses can be significantly reduced by an increase in government investment, compensation from disaster insurance and the mode of disaster management. For example, in the process of the post-Wenchuan earthquake restoration and reconstruction, the paired-assistance policy in China (i.e. 19 assistance provinces outside of the disaster-hit area offered financial assistance to 24 heavily impacted counties) shortened the reconstruction period from 3 to $2 \mathrm{yr}$ and significantly reduced the indirect loss (Hu, 2009). Overall, from the perspective of sustainable development, it is important to evaluate indirect loss of natural hazards.

The methods applied to evaluate the indirect impacts of disasters often include survey methods (e.g. Tierney, 1997; Boarnet, 1998), econometric models (e.g. Strobl, 2008), social accounting matrix multiplier (e.g. Cole, 1995), inputoutput (IO) models (e.g. Gordon et al., 1998; Hallegatte, 2008), computable general equilibrium (CGE) models (e.g. Rose et al., 1997, 2007; Rose and Liao, 2005; Tsuchiya et al., 2007; Xie et al., 2012) and hybrid physical-economic models (e.g. Booker, 1995; Holden and Shiferaw, 2004). Due to the request of long time series with sufficient numbers of events, econometric models are less applicable. The low precision of the assessment result, such as double counting or underestimation, leads survey methods seldom used. At present, IO models, CGE models and hybrid models (intermediary between CGE and IO) are more frequently used. These models are based on solid economic system theory and require data for a single disaster event. Nonetheless, the IO and CGE models have their own limitation when it comes to valuation of indirect loss of natural hazards. The linear character of IO models cannot reflect the substitution elasticity in the economic system. CGE models are inefficient in modeling the short-term evolution of the post-disaster economic system. Recently, hybrid models (intermediary between CGE and IO) have been developed. These intermediate models integrated the advantage of the IO and CGE models, e.g. CGE models with reduced substitution elasticity (Rose and Liao, 2005), IO models with flexibility (Hallegatte, 2008), or TERM model (Horridge et al., 2005) with bottom characteristics.

Two research strands on indirect economic loss resulting from disaster are worth noting. There is a significant body of assessing indirect impacts themselves which focus on increasing the precision of the assessment results. The ARIO model (Hallegatte, 2008) and the IIM model (Haimes, 2005) are such examples. The second strand aims at disaster reduction through assessing indirect loss. For instance, Rose and Liao (2005) designed CGE models with increased substitution elasticity to model economic resilience. In this research, resilience was represented by indirect loss. The policy suggestion regarding the reduction of indirect loss was to increase the regional economic resilience. The SCGE model, formulated by Tatano and Tsuchiya (2008), simulated the spatial impact of indirect loss. They found that in addition to the region directly affected by the hazards, indirect losses also occurred in remote zones of the country from the Niigata-Chuetsu earthquake of 2004. Therefore, some counter-measures should be implemented to stop the spatial spread of disaster impacts.

Our study fits into the latter category. The originality of this study lies in the evaluation of indirect economic loss (IEL) induced by hypothetical earthquakes in two regions in China with different levels of economic development. We use the measured direct loss of the $M_{\mathrm{S}}=8.0$ (earthquake magnitude is usually measured on a popular $M_{\mathrm{S}}$ scale of $0-10$. An $M_{\mathrm{s}}=8.0$ earthquake can destroy hundred miles area) earthquake in Wenchuan to transfer the results and methods to Shanghai area. This study estimated indirect economic loss due to the disruption of production processes (IEL I) and indirect economic loss induced by the disturbance of industrial lines (IEL II) using input-output models. Moreover, the reconstruction periods in both regions are given. The purpose is to discover the causes of different indirect impacts that occur in two regions and to provide potential measures for disaster reduction.

This article is organized in five sections. Section 2 subdivides IEL of natural hazards into two types in order to discover the causes of IEL and improves the published adaptive regional input output (ARIO) model (Hallegatte, 2008) to evaluate these two types of losses. Section 3 explains the study area and data. Section 4 evaluates the IEL and compares the economic systems of Shanghai and Sichuan province and tries to understand the root cause of IEL. Finally, Sect. 5 summarizes our findings and proposes insights for further research.

\section{Method}

This study primarily uses the ARIO model (Hallegatte, 2008) to assess IEL. This model had been applied to assess the indirect economic impacts of hurricane Katrina on Louisiana, of the sea-level rise on Copenhagen, of the flood on Mubai (Hallegatte et al., 2011a, b), and of the earthquake on Sichuan province (Wu et al., 2012). Those simulation results were found to be consistent with the available data. Based on definitions of the Przyluski and Hallegatte (2011) and the definition of the ARIO model, this section further divides IEL into IEL I and IEL II and improves the ARIO model to evaluate these two types of losses. 


\subsection{Subdivision of indirect economic loss}

In this study, direct loss refers to the portion of the remaining value added that has to be dedicated to reconstruction instead of normal consumption, i.e. repairing or replacement cost of the assets that have been damaged or destroyed (Hallegatte, 2008). Indirect loss refers to the reduction of the total value added by the economy, because of the disaster, including business interruption in the aftermath, production loss during the reconstruction period and service loss in the housing sector (Hallegatte, 2008). In Fig. 1, the left part shows the difference between direct and indirect loss. Here, we assume that the capital stock and the output value increase gradually and economic level returns to the economic level of pre-disaster period. For example, if a factory is damaged in an earthquake at time $t_{0}$, then the lost capital can be regained progressively from $t_{0}$ through the reconstruction (e.g. if 10 machines have been destroyed, first 3 , then 5 , then 8 , and finally all machines will have been repaired); there is a tendency to specify the decline in capital stock value (e.g. the replacement cost of the above-mentioned 10 machines) at $t_{0}$ as a direct loss. Indirect losses are highly variable and depend on the length of the "economic disruption", which is typically synonymous with the recovery and reconstruction periods. Indirect losses refer to the decline in output flow value during these periods, which can be calculated using the mathematical method of integration and are equal to the area of $\Delta \mathrm{abc}$ in the figure on the left. According to the causes of the indirect loss, we can call $\Delta$ abc indirect economic loss (IEL), which can be divided into two parts: $\Delta \mathrm{abd}$, indirect economic loss I due to the disruption of production processes (IEL I) (Bubeck and Kreibich, 2011) and $\Delta \mathrm{acd}$, indirect economic loss II induced by the disturbance of industrial chains (IEL II) (Przyluski and Hallegatte, 2011).

The right part of Fig. 1 shows the causes of IEL. For simplicity we chooses only one path in complex industry web and assume that there are three industries A, B and C in the economic system, as well as the final demand (FD). The earthquake will bring different levels of damage to A, B and $\mathrm{C}$, which will cause direct and indirect loss. Here, we focus on B's IEL. First, we divide B into $B_{1}$ (representing the completely destroyed part) and $B_{2}$ (representing the basically intact part). Because $\mathrm{B}_{1}$ has been completely destroyed, there is no IEL caused by the reduction of A's supply to B or C's demand for $\mathrm{B}$. Therefore, $\mathrm{B}_{1}$ 's IEL is due to the disruption of production processes. $\mathrm{B}_{1}$ 's IEL is named as IEL I, represented by $\Delta$ abd. Because $B_{2}$ is basically intact, there is no IEL caused by the disruption of production processes. $\mathrm{B}_{2}$ 's IEL is due to A's reduced supply of sufficient raw material and C's demand decline for up-stream products, i.e. the disturbance of industrial chains. $\mathrm{B}_{2}$ 's IEL is named as IEL II, represented by $\Delta \mathrm{acd}$. The total IEL is represented by $\Delta \mathrm{abc}$, which is composed of $\Delta \mathrm{abd}$ and $\Delta \mathrm{acd}$. Similarly, the IEL of sectors $\mathrm{A}$ and $\mathrm{C}$ can be divided into IEL I and IEL II.
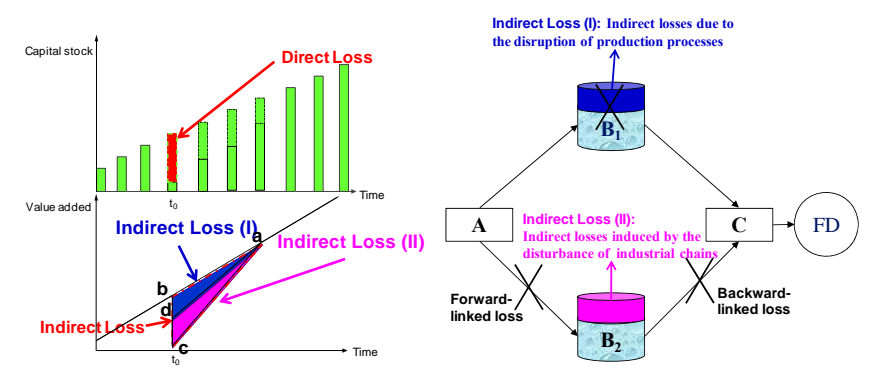

Fig. 1. Direct loss and indirect loss (the increase of capital stock and output value by degrees in baseline scenario is a strong assumption).

\subsection{Improvement of the ARIO model}

This dynamic model takes into account the changes in production capacity due to productive capital losses, production bottlenecks due to both forward and backward propagations within the economic system and adaptive behavior in the aftermath of disaster. We can calculate IEL I by assessing production ability changes and IEL II by assessing production bottlenecks and adaptive behavior.

\section{IEL I}

According to the Leontief Production Function, indirect economic losses due to the disruption of production process are directly proportionately to damaged stock capitals. Therefore, IEL I is

$\operatorname{Indirect} \operatorname{Loss}(\mathrm{I})=\sum_{t} \sum_{i} \bar{Y}(i) \frac{\tilde{D}(i, t)}{\beta(i) \operatorname{VA}(i)}$

In the above function, $t$ refers to the time step; $i$ refers to the industrial sector; $\bar{Y}(i)$ refers to the industrial sector $i$ 's production (month average) before the disaster; $\frac{\tilde{D}(i, t)}{\beta(i) \mathrm{VA}(i)}$ can be regarded as the reduction percentage of industry $i$ 's production at time $t ; \tilde{\mathrm{D}}(i, t)$ refers to the disaster damage to the capital stock of industrial sector $i$ at time $t ; \beta(i)$ is the average productivity ratio of industrial sector $i$; and $\mathrm{VA}(i)$ refers to the value added (VA) of industrial sector $i$.

\section{IEL II}

IEL II is estimated by using $B_{2}$ of Fig. 1 as an example. After the earthquake, the production of sector $\mathrm{A}$ declines and can no longer meet the demand of industrial sector $B_{2}$. Sector $\mathrm{B}_{2}$ contributes to part of IEL II because of this forwardlinked impact of A. $Y^{2}(i)$ calculated from the ARIO model (see Hallegatte, 2008 for details) is the production of $\mathrm{B}_{2}$ after this forward-linked impact. Similarly, after the earthquake, the production of industrial sector $\mathrm{C}$ declines and may reduce the demand from industrial sector $B_{2}$. Sector $B_{2}$ contributes to part of IEL II because of the backward-linked impact of C. $Y^{\infty}(i)$, calculated from the ARIO model, is the production 
Table 1. Comparison table of 2010 socio-economic profile in two regions

\begin{tabular}{lrr}
\hline & Shanghai & Sichuan \\
\hline Land area $\left(\mathrm{km}^{2}\right)$ & 6340.5 & 48500.0 \\
Population at year-end $(10000$ persons) & 2303 & 8045 \\
Population density (persons per km $\left.{ }^{2}\right)$ & $3632(2.2)^{* *}$ & 1659 \\
Urbanization rate $(\%)^{*}$ & $85.71(3.5)$ & 24.74 \\
GDP (100 million yuan) & 17165.98 & 17185.48 \\
GDP per capita (yuan) & $76074.49(3.6)$ & 21182.00 \\
GDP per capita ranking in 31 provinces of Mainland China & $1 / 31$ & $25 / 31$ \\
\hline
\end{tabular}

Data source: DRCNET Statistical Database System; Shanghai Statistical Yearbook 2011; Sichuan Statistical Yearbook 2011. * Due to the unavailability concerning the nonagricultural population in 2010, urbanization rate is total population divided by nonagricultural population from 2008. ${ }^{* *}$ The number in the brackets is the multiple of Shanghai compared with Sichuan.

of $\mathrm{B}_{2}$ after the forward-linked and backward-linked impacts. Therefore, the part of IEL II caused by the backward-linked impact equals the difference between $Y^{\infty}(i)$ from $Y^{2}(i)$. We note that sector $\mathrm{B}_{2}$ may face a reduction in production after being affected by sector $\mathrm{A}$ and $\mathrm{C}$ in the first round. But when sectors $\mathrm{A}$ or $\mathrm{C}$ are affected by other sectors, such as sectors $\mathrm{D}, \mathrm{E}$ or $\mathrm{F}$, they may have an impact on sector $\mathrm{B}_{2}$ in the second round. By analogy, $\mathrm{B}_{2}$ may be affected in countless rounds. It seems that IEL II of $\mathrm{B}_{2}$ may be double counted. In fact, this seemingly endless process will end only when supply equals demand in all of the sectors. At the time point when this occurs, the economic system enters into an equilibrium state, and the production of $\mathrm{B}_{2}$ will not decline. In the ARIO model, $Y^{\infty}(i)$ and $T D^{\infty}(i)$ are, respectively, the final supply and the final demand of every sector when the economic system is at equilibrium. $Y^{\infty}(i)$ and $T D^{\infty}(i)$ are the results of an iteration calculation, ending when $Y^{\infty}(i)=T D^{\infty}(i)$. Broadly speaking, the ARIO model avoids any potential double-counting of the impact to every sector.

After modeling the forward-linked impact and the backward-linked impact along the industrial chain, we can develop IEL II:

Indirect $\operatorname{Loss}(\mathrm{II})=$

$$
\sum_{t} \sum_{i}\left[\bar{Y}(i)-\bar{Y}(i) \frac{\tilde{D}(i, t)}{\beta(i) \operatorname{VA}(i)}-Y^{\infty}(i, t)\right]
$$

\section{IEL}

From the previous definitions and the classification of IEL, we can calculate the following:

Total Indirect Loss $=$ Indirect Loss (I)+ Indirect Loss (II)

Total Indirect Loss $=\sum_{t} \sum_{i}\left[\bar{Y}(i)-Y^{\infty}(i, t)\right]$

\section{The study area and data}

\subsection{The study area}

In 2008, an $M_{\mathrm{S}}=8.0$ earthquake jolted Wenchuan County of Sichuan Province, China, bringing a death toll of over 80000 (NDRC, 2008), a total direct loss of Chinese Yuan (CNY) of 845.2 billion (the exchange rate of CNY to USD is 0.14 in 2008) for the combined Sichuan, Gansu and Shannxi Provinces (NCDR, 2008) and an indirect economic loss (IEL) of CNY 301 billion for Sichuan Province (Wu et al., 2012). After this event, disaster reduction organizations and scientists in China began to analyze the potential aftermath of a similarly severe earthquake occurring in a developed area in China (e.g. the Shanghai or Beijing municipalities). To evaluate and compare indirect economic losses (IEL) of two scenario earthquakes occurring in two regions with different economic development levels, this study chooses developed Shanghai and compares it to less developed Sichuan. Sichuan province lies in the south-west region of China with a high altitude, whereas Shanghai municipality lies in the coastal region in eastern China with a low altitude (see Fig. 2). One earthquake of above $M_{\mathrm{s}}=7.0$ and five tsunamis have struck Shanghai during its history. Based on historical data, most of the earthquakes occurring in Shanghai were shallow focus earthquakes, which had fatal consequences. Importantly, Shanghai is economically developed, forming a sharp contrast with Sichuan (see Fig. 2 and Table 1). In recent years, the gross domestic production (GDP) growth rate of Shanghai has always been higher than that of Sichuan. In the composition of economic branches, share of the secondary and the tertiary in these two regions both increased, but share of the both in Shanghai were always larger than that of Sichuan. The population density of Shanghai was 2.2 times that of Sichuan in 2010. The urbanization rate of Shanghai was 3.5 times that of Sichuan in 2008. The GDP per capita of Shanghai was 3.6 times that of Sichuan in 2010. In the 31 provinces of Mainland China, the GDP per capita of Shanghai ranked first, whereas that of Sichuan ranked 25th in 2010. 


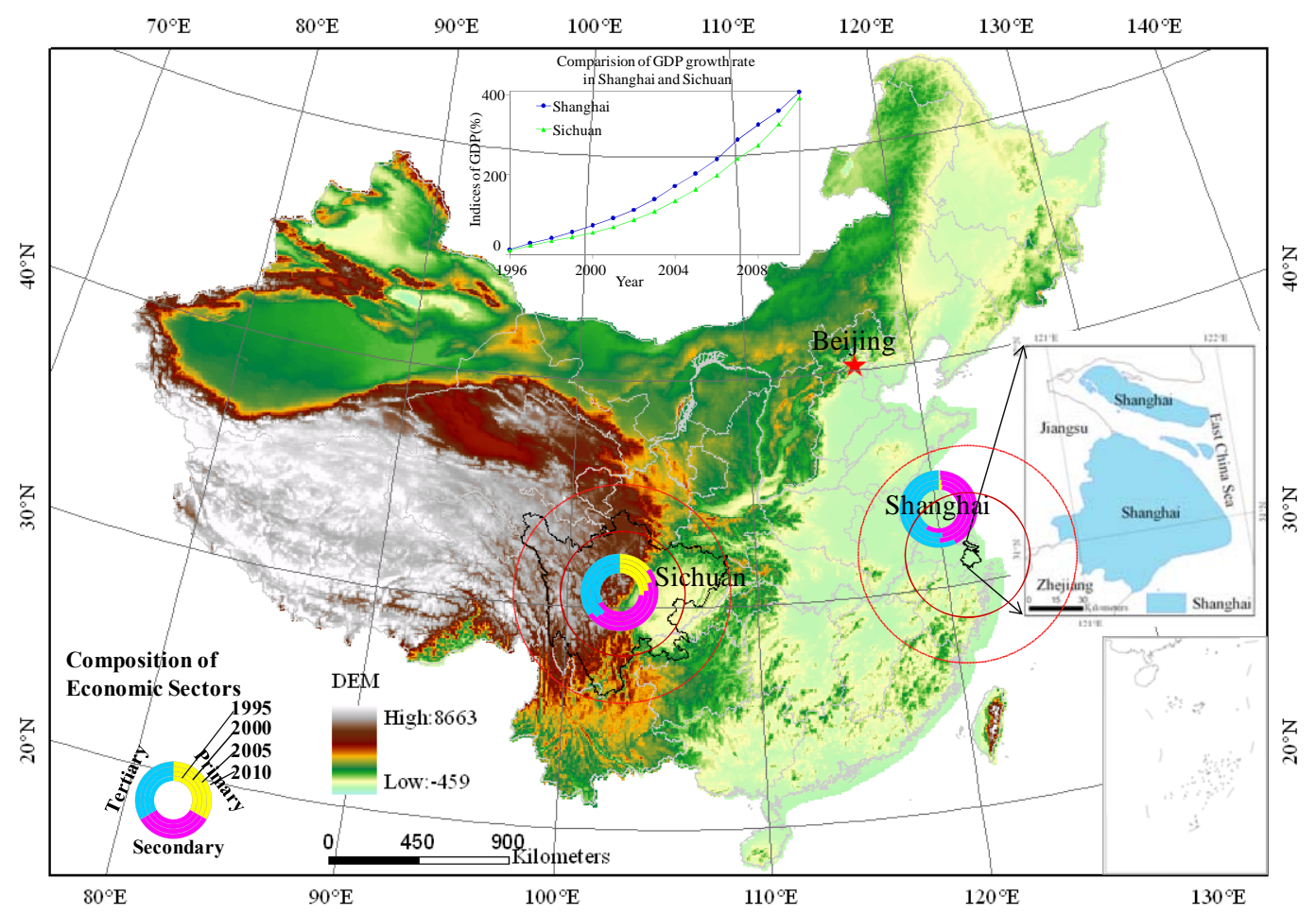

Fig. 2. The study area (GDP is calculated at constant prices, year of $2005=100)$.

\subsection{Data and parameters}

In this paper, four sets of data were used for the ARIO model. First, the 2002 input-output (IO) tables for Sichuan Province and Shanghai Municipality, obtained from the Chinese Bureau of Statistics, were used for building the ARIO sectors. In the IO table, the former 42 sectors were aggregated to form 17 new sectors (Appendix A). As such, the local economy was composed of 17 productive sectors and one household sector. We note that the Chinese IO table is surveyed once every $5 \mathrm{yr}$ and the $2007 \mathrm{IO}$ table for every province is still being adjusted; therefore, this study uses the corrected 2002 IO table. This choice has little impact on the purpose of this study because the aim is to compare the IEL between Sichuan with that Shanghai, rather than estimating the absolute IEL of the two earthquakes.

Second, the sector-by-sector distributed direct loss of the Wenchuan earthquake was taken from the National Commission for Disaster Reduction and the Ministry of Science and Technology of China (NCDR, 2008). These sources provided a comprehensive estimate of direct losses. These data had been merged from the source data by sectors and had been revised to subtract any losses that could not be repaired, replaced or rebuilt (e.g. ecological losses).

Third, by using the direct loss to every industrial sector caused by Wenchuan earthquake in 2008, the direct loss to every industrial sector of Shanghai and Sichuan Province caused by a hypothetical $M_{\mathrm{s}}=8.0$ earthquake in $2002 \mathrm{can}$ be calculated as follows:

$$
\begin{aligned}
& \operatorname{DL}(s, p, 2002)= \\
& \frac{\operatorname{DL}(s, \text { Wenchuan, 2008) }}{\operatorname{CAP}(s, \text { Wenchuan, 2008) }} \times \operatorname{CAP}(s, p, 2002)
\end{aligned}
$$

where $s$ refers to the industrial sectors in Table A1 and $p$ refers to either Shanghai or to Sichuan Province. $\mathrm{DL}(s, p, 2002)$ represents the direct loss of the $s$ industrial sector in location $p$ in 2002; $\operatorname{CAP}(s, p, 2002)$ represents the capital stock value of the $s$ industrial sector in location $p$ in 2002. This method is, of course, a simplistic way of calculating the direct loss of every industry. This study aims to calculate the difference in the level of IEL for different economic systems given the same level of direct loss. Therefore, as a first step, this rough estimate of the sector-by-sector distributed direct loss is assumed to be sufficient.

Fourth, the parameter values are listed in Table 2. The maximum production capacity after the earthquake is set as $125 \%$ thanks to central post-quake restoration and reconstruction fund established by Chinese central finance and paired-assistance fund established by 19 assistance provinces outside of the disaster-hit area. The modeling time step width was one month. These parameters are identical to those used in indirect economic impact evaluation of Wenchuan earthquake (Wu et al., 2012), and they take unique Chinese disaster relief policies into account. Thus, they are credible. 
Table 2. Parameter values in the ARIO model.

\begin{tabular}{lll}
\hline Name & Value & Description \\
\hline$a_{b}$ & $100 \%$ & Production capacity pre-earthquake \\
$a_{\max }$ & $125 \%$ & Maximum production capacity post-earthquake \\
$\tau$ & 6 months & Adaptation time \\
$\varepsilon$ & 0.9 & Elasticity of local final demand with respect to the commodity price \\
\hline
\end{tabular}
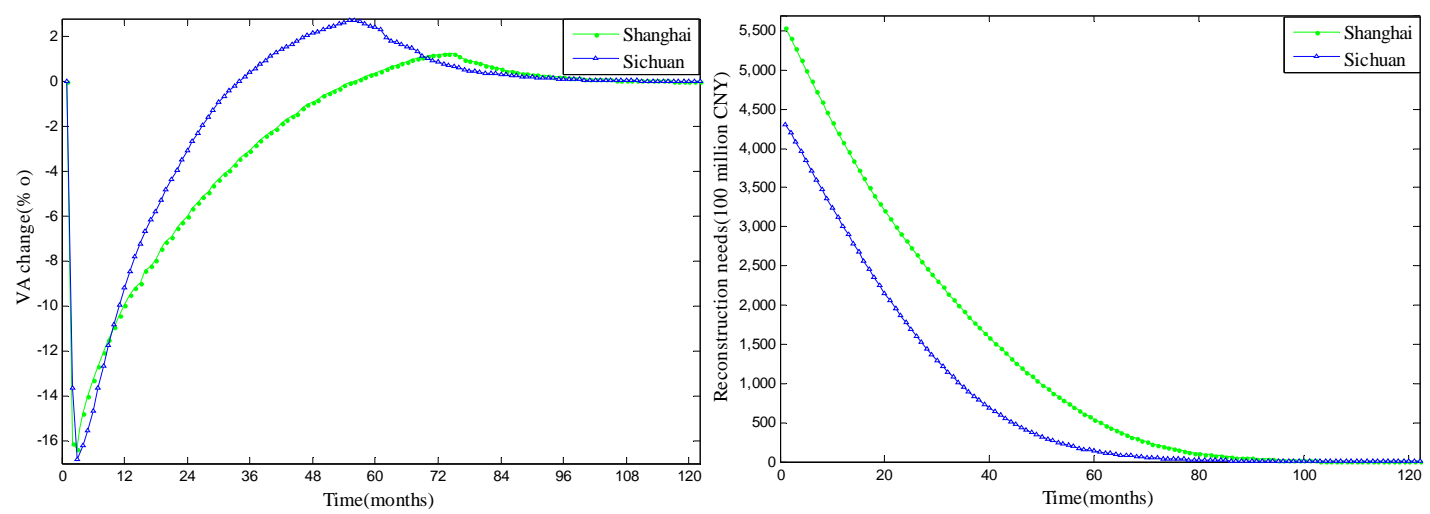

Fig. 3. Change in total VA (\% of the pre-earthquake level, left panel) and reconstruction needs (in billion CNY, right panel) as a function of time for a hypothetical $M_{\mathrm{S}}=8.0$ earthquake in Shanghai and Sichuan Province.

\section{Evaluation results and attribution analysis}

\subsection{Evaluation results}

Based on the ARIO model and the above data and parameters, we can simulate how the value added recovers to the predisaster level and how the reconstruction needs change after the hypothetical $M_{\mathrm{s}}=8.0$ earthquake occurring in Shanghai Municipality and Sichuan Province. The IEL is measured in terms of value added to avoid double-counting issues. In Fig. 3, the figure on the left shows the evolution of value added (in percent of pre-quake level) of Shanghai and Sichuan from the stricken time to full recovery. For most of the post-disaster period, the decline of Shanghai's value added is greater than that of Sichuan. We should note that in the whole reconstruction period, the total value added sometimes surpasses the initial production level thanks to reconstruction activity, and the decline of Shanghai's value added is sometimes less than that of Sichuan due to instabilities in adaptation process (Hallegatte, 2008). In Fig. 3, the figure on the right shows how the reconstruction demands change. During the reconstruction period, the capital demand for Shanghai is consistently greater than that of Sichuan. Regardless of the evolution of value added or the capital demand from reconstruction, reconstruction in Shanghai is completed after approximately 121 months, whereas reconstruction in Sichuan is completed after approximately 115 months. In other words, Shanghai will recover half a year later than Sichuan.
After the earthquake, the respective direct and indirect losses of Shanghai and Sichuan are shown in Table 3. When the two areas both suffer CNY 100 of direct loss, the IEL of Sichuan is CNY 32, whereas that of Shanghai is CNY 44. In other words, for every CNY 100 of direct loss, Shanghai suffers CNY 12 more of indirect loss than Sichuan does. This comparison indicated that developed regions may be more vulnerable with respect to IEL.

According to definitions of direct and indirect loss, particularly for the subdivision of IEL, this study uses the ARIO model to assess sector per sector IEL I and IEL II in Shanghai and Sichuan and then compares the quantitative relationship between the two types of IEL. Table 4 demonstrates that every sector in both Shanghai and Sichuan suffers IEL I. If direct loss makes up the same proportion of fixed asset in every industrial sector, then IEL I for every industrial sector in Shanghai is approximately 1.25 times that of every industrial sector in Sichuan. The No. 8 and No. 12 industries in Shanghai benefit from IEL II and the No. 6, No. 8 and No. 12 industries in Sichuan benefit from IEL II. The rest of the industries suffer from IEL II.

On aggregate, the level of IEL I suffered by Shanghai is 1.44 times that suffered by Sichuan, whereas the level of IEL II suffered by Shanghai is 4.09 times that suffered by Sichuan. This 1.44 is defined as "multiple number" of IEL I. Similarly, 4.09 is defined as "multiple number" of IEL II. Obviously, "multiple number" of IEL II (4.09) is higher than "multiple number" of IEL I indicating that decision makers also need to focus on IEL II beside IEL I which is usually the 
Table 3. Comparison of the direct loss and indirect loss in Shanghai and Sichuan.

\begin{tabular}{lrrr}
\hline Area & $\begin{array}{r}\text { Direct Loss } \\
\text { (in ten thousand CNY) }\end{array}$ & $\begin{array}{r}\text { Indirect Loss } \\
\text { (in ten thousand CNY) }\end{array}$ & Indirect/Direct \\
\hline Shanghai & 5549.1 & 2415.3 & $44 \%$ \\
Sichuan & 4311.3 & 1382.8 & $32 \%$ \\
$\Delta$ (Shanghai-Sichuan) & - & - & $12 \%$ \\
\hline
\end{tabular}

Table 4. Economic impact of an earthquake occurring in Shanghai and Sichuan Provinces, 2002.

\begin{tabular}{|c|c|c|c|c|c|c|c|c|}
\hline \multirow{3}{*}{ Sector No. } & \multirow{2}{*}{\multicolumn{2}{|c|}{ Output Baseline }} & \multicolumn{5}{|c|}{ Output Change after Earthquake } & \\
\hline & & & \multicolumn{3}{|c|}{ IEL I } & \multicolumn{3}{|c|}{ IEL II } \\
\hline & $\begin{array}{r}\text { Shanghai } \\
\text { (in } 100 \text { million } \\
\mathrm{CNY})(1)\end{array}$ & $\begin{array}{r}\text { Sichuan } \\
\text { (in } 100 \text { million } \\
\mathrm{CNY})(2)\end{array}$ & $\begin{array}{r}\text { Shanghai }^{\mathrm{a}} \\
\text { (3) }\end{array}$ & $\begin{array}{r}\text { Sichuan }^{\mathrm{a}} \\
(4)\end{array}$ & $\begin{array}{l}\text { Shanghai/ } \\
\text { Sichuan }^{b} \\
(5)=(3) /(4)\end{array}$ & $\begin{array}{r}\text { Shanghai }^{\mathrm{a}} \\
(6)\end{array}$ & $\begin{array}{r}\text { Sichuan }^{\mathrm{a}} \\
\text { (7) }\end{array}$ & $\begin{array}{r}\text { Shanghai/ } \\
\text { Sichuan }^{b} \\
(8)=(6) /(7)\end{array}$ \\
\hline 1 & 249.8 & 1615.4 & $-0.03 \%$ & $-0.03 \%$ & 1.25 & $-1.09 \%$ & $-0.90 \%$ & 1.21 \\
\hline 2 & 32.6 & 405.3 & $-0.10 \%$ & $-0.08 \%$ & 1.25 & $-0.84 \%$ & $-0.54 \%$ & 1.54 \\
\hline 3 & 597.9 & 848.1 & $-0.18 \%$ & $-0.14 \%$ & 1.25 & $-1.60 \%$ & $-1.04 \%$ & 1.54 \\
\hline 4 & 819.4 & 166.5 & $-0.18 \%$ & $-0.14 \%$ & 1.25 & $-1.67 \%$ & $-1.08 \%$ & 1.54 \\
\hline 5 & 524.4 & 305.7 & $-0.18 \%$ & $-0.14 \%$ & 1.25 & $-1.47 \%$ & $-0.58 \%$ & 2.55 \\
\hline 6 & 258.2 & 18.9 & $-0.08 \%$ & $-0.06 \%$ & 1.25 & $-0.41 \%$ & $1.79 \%$ & -0.23 \\
\hline 7 & 1341.9 & 515.7 & $-0.18 \%$ & $-0.14 \%$ & 1.25 & $-1.57 \%$ & $-0.42 \%$ & 3.74 \\
\hline 8 & 258.2 & 499.0 & $-0.18 \%$ & $-0.14 \%$ & 1.25 & $0.88 \%$ & $0.60 \%$ & 1.47 \\
\hline 9 & 802.8 & 515.6 & $-0.17 \%$ & $-0.14 \%$ & 1.25 & $-0.75 \%$ & $-0.26 \%$ & 2.92 \\
\hline 10 & 4671.7 & 1065.0 & $-0.18 \%$ & $-0.14 \%$ & 1.25 & $-1.59 \%$ & $-0.90 \%$ & 1.77 \\
\hline 11 & 345.9 & 389.2 & $-0.18 \%$ & $-0.14 \%$ & 1.25 & $-1.40 \%$ & $-0.76 \%$ & 1.85 \\
\hline 12 & 1154.2 & 1361.7 & $-0.10 \%$ & $-0.08 \%$ & 1.25 & $4.92 \%$ & $3.61 \%$ & 1.36 \\
\hline 13 & 1429.5 & 662.1 & $-0.16 \%$ & $-0.13 \%$ & 1.25 & $-0.97 \%$ & $-0.78 \%$ & 1.24 \\
\hline 14 & 1338.7 & 1064.3 & $-0.16 \%$ & $-0.13 \%$ & 1.25 & $-1.12 \%$ & $-0.75 \%$ & 1.50 \\
\hline 15 & 1729.7 & 561.4 & $-0.14 \%$ & $-0.11 \%$ & 1.25 & $-1.25 \%$ & $-1.08 \%$ & 1.16 \\
\hline 16 & 256.9 & 88.6 & $-0.07 \%$ & $-0.05 \%$ & 1.25 & $-0.77 \%$ & $-0.99 \%$ & 0.78 \\
\hline 17 & 937.2 & 893.4 & $-0.18 \%$ & $-0.14 \%$ & 1.25 & $-1.63 \%$ & $-1.41 \%$ & 1.16 \\
\hline Total & 16748.9 & 11510.8 & $-0.16 \%$ c & $-0.11 \% \mathrm{c}$ & $1.44^{\mathrm{d}}$ & $-0.90 \%$ c & $-0.22 \% \mathrm{c}$ & $4.09^{d}$ \\
\hline
\end{tabular}

${ }^{a}$ From the ARIO simulation. ${ }^{b}$ Multiple number of IEL I or IEL II. ${ }^{c}$ Weighted average of loss ratio occurred in every industry and the weight equals the ratio of output in every industry to total output ${ }^{d}$ the Shanghai/Sichuan ratio in the total row is higher than the ratio of any individual industry because the loss ratio and the output (i.e. weight) are high for some industries of Shanghai, but the opposite is true for Sichuan.

main disaster-reduction target after a disaster. From the comparison in Table 4, a dividend result is concluded: whether in Shanghai or Sichuan, IEL II is higher than IEL I, which indicates that IEL II is the primary factor contributing to total IEL.

\subsection{Attribution analysis}

In this section, the differences in the industrial linkages, the industrial structures and the regional trade of Shanghai and Sichuan are analyzed to discover which factors cause the marked differences in the IEL and reconstruction period to improve the government's disaster management ability.

\subsubsection{Inter-industrial Linkage}

Industrial backward linkages (IBL) is the increase/decrease in total output of the system required to utilize the
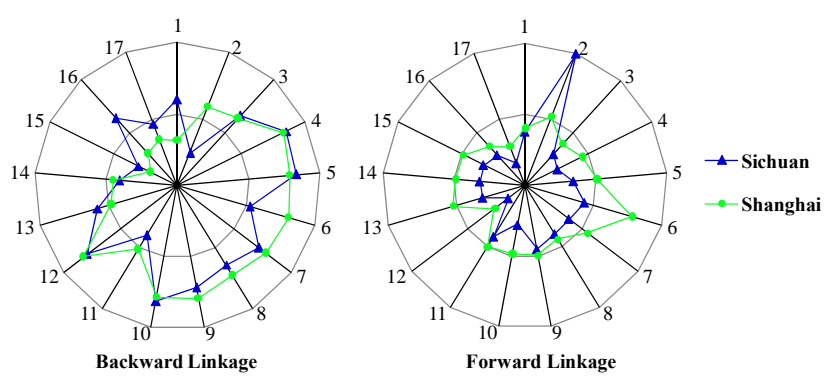

Fig. 4. Comparison of IBL and IFL for the 17 industries in Shanghai and Sichuan.

increased/decrease output from an initial unit of primary input into any one of the industrial sectors. Industrial forward linkages (IFL) is the increase/decrease in total output 


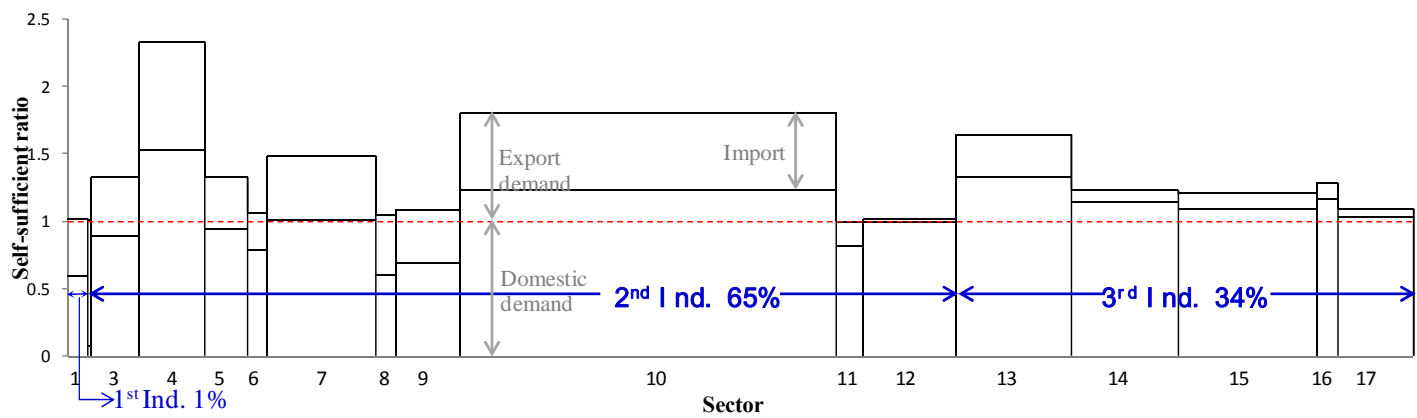

Shanghai Municipality

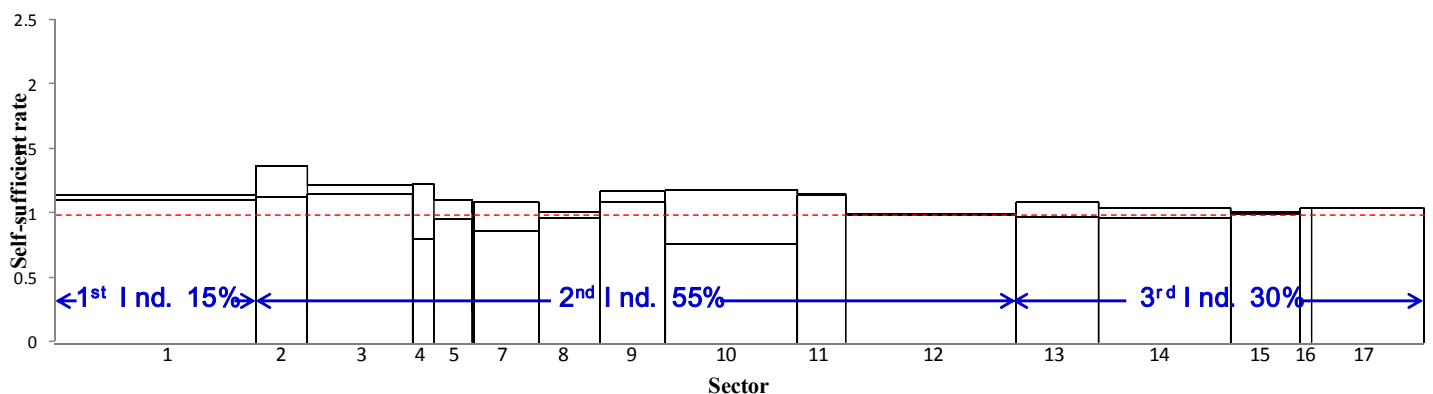

Sichuan Province

Fig. 5. Comparison of the industrial structures and trade in Shanghai and Sichuan (Please refer to the 10th industry of Shanghai) (Primary Industry: No. 1; Secondary Industry: No. 2 through No. 12; Tertiary Industry: No. 13 through No. 17).

of the system required to supply inputs for an initial unit increase/decrease in any one of the industrial sectors (Jones, 1976). According to the input-output table of Shanghai and Sichuan in 2002 and the IFL and IBL calculation method of Jones (1976), the IFL and IBL of the 17 industries in Shanghai and Sichuan are calculated. The result can be seen in Fig. 4. The figure on the right shows that the forward linkages of 16 of the 17 industries in Shanghai are more significant than those of Sichuan (i.e. damage to any of the 16 will more significantly affect their supply to the other industries). Even in the figure on the left, the backward linkages of over half industries in Shanghai are equal to or more than those of Sichuan. The comparison of backward linkages indicates that after the earthquake, the demand for raw material from the upstream industries declines, which will restrain the total production of the upstream industries for a lengthy period of time and will reduce the production of all of industries. Also as some published literatures pointed out, most of the indirect losses are caused by forward linkages (Haimes et al., 2005; Okuyama, 2007; Hallegatte, 2008). For example, upstream industries cannot provide sufficient raw material for downstream industries due to damaged factories and equipments. These forward linkages have more significant effects and deserve more consideration than backward linkages. So in terms of the relative loss of the total production of the entire industry, Shanghai suffers more relative loss than Sichuan. This comparison explains in Table 4 that most of the industries in Shanghai see a higher IEL II than those of Sichuan. In addition, the "multiple number" of IEL II (4.09) is higher than "multiple number" of IEL I. This difference occurs because the industries in Shanghai are more closely linked, which slows reconstruction. Therefore, over the same period of time, Shanghai has greater difficulty in restoring fixed capital such as damaged factories and equipment; these difficulties, in return, increase IEL I.

\subsubsection{Industrial structure and trade}

In terms of industrial linkage, we analyze the relative difference of IEL. To prove that the absolute value of Shanghai's IEL is larger than Sichuan, and that reconstruction will take Shanghai longer to complete, the industrial structures and trade of the provinces must be analyzed. In other words, the analysis of the industrial structures will show the weights of industries, which proves that Shanghai's absolute IEL may be greater. Figure 5 shows the industrial structures and trade in Shanghai and Sichuan. The width of the bar denotes the sector share of gross output. The height of the bar denotes the sum of domestic and export demand. Domestic demand is expressed as $100 \%$. The solid line between every pillar represents the degree of self-sufficiency. When the self-sufficiency degree is higher than the domestic demand (100\%), the industry is self-sufficient; otherwise, the industry requires a net import supply. 
In terms of industrial structure, the output proportions of the secondary and tertiary industries in Shanghai are larger than those of Sichuan. In particular, the output proportions of the secondary industries in Shanghai are $10 \%$ larger than those of Sichuan. From Fig. 4, we can see that most of the industries with larger forward and backward linkages are secondary industries. These two phenomena prove that Shanghai's IEL II is larger than Sichuan's in terms of absolute value. In addition, as can be seen in Fig. 4, the bar representing Shanghai is higher than Sichuan, and many of the industries in Shanghai have a self-sufficiency level less than $100 \%$. These two marked differences prove that Shanghai's trade intensity is much stronger than that of Sichuan. The ARIO model simulates the impacts of mutual trade between a disaster-hit zone and the outside areas on indirect losses. For Shanghai, which has intense trade, the break-down of infrastructure such as communications and transportation can damage regional trade, making the import of reconstruction materials, as well as the export of products, difficult. It is important to mention that intense trade is like a "double-edged sword" to IEL. On the one hand, it has lower multiplier effects. On the other hand, it blocks imports from outside of disaster-hit zones in emergency period. In the case of Shanghai, the benefits of intense trade are offset by other factors such as industrial technology, determining industrial multiplier effects (see Fig. 4).

Once the disaster occurs, neither the direct loss nor the IEL I can be reduced, whereas the IEL II can be reduced through non-structural measures such as the improvement of industrial linkages, industrial structures and regional trade. In addition, IEL II is much larger than IEL I. Thus, to reduce total economic losses during the reconstruction period, reducing IEL II via non-structural measures is recommended.

\section{Conclusions and discussion}

With simulation from an input-output model, this study evaluates indirect loss of hypothetical earthquakes occurring in developed Shanghai and less developed Sichuan in China. According to the comparison among industrial structures, industrial linkages and regional trade, the potential causes of different relationship variations in IEL are analyzed. First, one figure is drawn to demonstrate the difference between direct and indirect economic loss; the other figure is drawn to explain that IEL can be further divided into IEL I due to the disruption of production process and IEL II induced by the disturbance of industrial lines; Second, the two types of IEL are evaluated by using an improved version of the ARIO model. The simulation results compare the evolution of production from the stricken time to full recovery, reconstruction needs and recovery durations. More importantly, the multiple number for both IEL I and IEL II are compared. Third, we analyze the causes of IEL in terms of industrial linkages, industrial structures and trade to explain why the multiple number of IEL II is larger than that of IEL I. For the purpose of disaster risks governance, three conclusions are drawn in this study.

Assuming the same relative direct losses, Shanghai would suffer more relative indirect loss than Sichuan. Of the per CNY 100 direct loss, Shanghai suffers CNY 12 more indirect losses than Sichuan does. During the reconstruction period, Shanghai will require half a year longer to recover. The comparison indicates that developed regions may be more vulnerable with respect to IEL. Therefore, policy makers are advised to pay more attention to the indirect loss in developed areas.

Both Shanghai and Sichuan suffer more in IEL II than in IEL I, which indicates that IEL II is the primary factor contributing to total IEL. The level of IEL II suffered by Shanghai is 4.09 times that suffered by Sichuan, whereas the level of IEL I suffered by Shanghai is only 1.4 times that suffered by Sichuan. This comparison indicates that decision makers also need to focus on IEL II beside IEL I which is usually the main disaster-reduction objective after a disaster.

Shanghai's development in recent years demonstrates a significant contribution of an optimized industrial structure, closely linked industries and intense trade to regional economic growth. However these factors will also increase disaster risk. Therefore, tradeoff between economic growth and disaster prevention is needed to achieve regional sustainable development. The reduction of indirect loss should be a part of the overall process of disaster risk governance. Before the disaster, governments should adjust and optimize the industrial structure; and after the disaster, governments should give priority to the recovery of infrastructure system and the industries with more linkages to promote economic recovery.

Overall, this study evaluates and compares the indirect loss of hypothetical earthquakes in two regions with different economic development level to try to provide new measures of disaster reduction. But it is not sufficient to answer the connection from disaster loss to development and wealth. The published literature mainly investigates this subject using econometric methods. The improved ARIO model, like a laboratory of economic system, is such a promising approach to evaluate indirect loss of disasters occurred in areas with different economic development level that can be developed to study the connection between indirect effects and development from a new perspective. 
Table A1. ARIO model sectors.

\begin{tabular}{ll}
\hline $\begin{array}{l}\text { Sector } \\
\text { No. }\end{array}$ & $\begin{array}{l}\text { ARIO } \\
\text { sector }\end{array}$ \\
\hline 1 & Agriculture \\
2 & Mining Industry \\
3 & Food Manufacturing \\
4 & Textile, Sewing Machine and Leather \\
& Manufacturing \\
5 & Wood Processing \& Furniture Manufacturing \\
6 & Coke, Gas \& Oil Processing \\
7 & Chemical Industry \\
8 & Construction Material \& Other Nonmetallic \\
& Mineral Manufacturing \\
9 & Metallic Products Manufacturing \\
10 & Mechanical Equipment Manufacturing \\
11 & Electricity, Steam, Hot-water Production \\
& \& Supply \\
12 & Building Trade \\
13 & Transportation, Post \& Telecommunications \\
14 & Commerce \& Catering \\
15 & Finance \& Insurance \\
16 & Specific Service Management \\
17 & Public Utility \& Resident Service \\
\hline
\end{tabular}

Acknowledgements. This research was supported by National Natural Science Foundation of China (No. 41171401; No. 41101506), National Basic Research Program of China (No. 2012CB955402), International Cooperation Program (No. 2012DFG20710) and ESPRE (No. 2012-TDZY-022). The authors thank Ying Gao, Saini Yang and Zhonghui Ji from Beijing Normal University for their valuable suggestions and careful revision of this paper. Cordial thanks should be given to the editor Thomas Glade, and two anonymous referees for their constructive suggestions and comments that greatly helped to improve the quality of this article.

Edited by: T. Glade

Reviewed by: two anonymous referees

\section{References}

Benson, C. and Clay, E.: The impact of drought on sub-Saharan African economies, Technical paper 401, The World Bank, Washington, DC, 1998.

Benson, C. and Clay, E.: Understanding the Economic and Financial Impacts of Natural Disasters, Disaster Risk Management Series No. 4, The World Bank, Washington, DC, 2004.

Boarnet, M. G.: Business losses, transportation damages, and the Northridge earthquake, J. Transport. Stat., 1, 49-63, 1998.

Booker, J. F.: Hydrologic and economic impacts of drought under alternative policy responses, Water Resour. Bull., 31, 889-906, 1995.

Bubeck, P. and Kreibich, H.: Natural Hazards: direct costs and losses due to the disruption of production processes, in: $\mathrm{CON}$ HAZ report WP01_2 supported by the European Community's Seventh Framework Program through the grant to the budget of the Coordination Action CONHAZ, Contract 244159, Potsdam, German, 68 pp., 2011.

Cole, S.: Lifelines and livelihood: a social accounting matrix approach to calamity preparedness, J. Contingencies Crisis Manage., 3, 228-240, 1995.

ECLAC (Economic Commission for Latin America and the Caribbean): Handbook for Estimating the Socio-economic and Environmental Effects of Disaster, Economic Commission for Latin America and the Caribbean, Santiago, Chile, 2003.

FEMA (Federal Emergency Management Agency): HAZUS 99 estimated annualized losses for the United States, Publication No. 366, Federal Emergency Management Agency, Washington DC, 2001.

Gordon, P., Richardson, H., and Davis, B.: Transport-related impacts of the Northridge earthquake, J. Transport. Stat., 1, 21-36, 1998.

Haimes, Y., Horowitz, B., Lambert, J., Santos, J., Lian, C., and Crowther, K.: Inoperability input-output model for interdependent infrastructure sectors. I: Theory and methodology, J. Infrastruct. Syst., 11, 67-79, 2005.

Hallegatte, S.: An adaptive regional input-output model and its application to the assessment of the economic cost of Katrina, Risk Analys., 28, 779-799, 2008.

Hallegatte, S., Henriet, F., and Corfee-Morlot, J.: The economics of climate change impacts and policy benefits at city scale: a conceptual framework, Climate Change, 104, 51-87, 2011a.

Hallegatte, S., Ranger, N., Mestre, O., Dumas, P., Corfee-Morlot, J., Herweijer, C., and Wood, R.: Assessing climate change impacts, sea level rise and storm surge risk in port cities: a case study on Copenhagen, Climate Change, 104, 113-137, 2011 b.

Holden, S. and Shiferaw, B.: Land degradation, drought and food security in a lessfavoured area in the Ethiopian highlands: a bioeconomic model with market imperfections, Agr. Econom., 30, 31-49, 2004.

Horridge, M., Madden, J., and Wittwer, G.: The impact of the 2002 2003 drought on Australia, J. Policy Model., 27, 285-308, 2005.

Hu, J. T.: Struggling to accomplish primary three years reconstruction task in two years, available at: http://politics.people.com.cn/ GB/1024/9286158.html (last access: 26 July 2012), 2009.

IPCC: Managing the risks of extreme events and disasters to advance climate change adaptation, in: Special report of the intergovernmental panel on climate change (IPCC), edited by: Field, C. B., Barros, V., Stocker, T. F., Qin, D., Dokken, D., Ebi, K. L., Mastrandrea, M. D., Mach, K. J., Plattner, G.-K., Allen, S. K., Tignor, M., and Midgley, P. M., United Kingdom and New York, NY, USA, 582 pp., 2012.

ISDR, CRED and UCL: Annual Disaster Statistical Review: Numbers and Trends 2007, Authors: Scheuren, J. M., Waroux, O. P., Below, R., Guha-Sapir, D., and Ponserre, S., Brussels, Belgium, 47 pp., 2008.

Jones, L. P.: The Measurement of Hirschmanian Linkages, Q. J. Econom., 90, 323-333, 1976.

Loayza, N. V., Olaberria, E., Rigolini, J., and Christiaensen, L.: Natural Disasters and Growth: Going Beyond the Averages, World Development, 40, 1317-1336, 2012.

NCDR (National Commission for Disaster Reduction), MOST (Ministry of Science and Technology of China): Wenchuan earthquake disaster: a comprehensive analysis and evaluation, Science Press, Beijing, 166-174, 2008. 
NDRC (National Development and Reform Committee of China): The state overall planning for the post-Wenchuan earthquake restoration and reconstruction, available at: http://en.ndrc.gov.cn/ policyrelease/P02008101062622006749250.pdf, last access: 17 October 2009, 2008.

Okuyama, Y.: Economic Modeling for Disaster Impacts Analysis: Past, Present, and Future, Econom. Syst. Res., 19, 115-124, 2007.

Pelling, M., Özerdem, A., and Barakat, S.: The macro-economic impact of disasters, Prog. Develop. Studies, 2, 283-305, 2002.

Przyluski, V. and Hallegatte, S.: Indirect Costs of Natural Hazards, in: CONHAZ report WP02_2 supported by the European Community's Seventh Framework Program through the grant to the budget of the Coordination Action CONHAZ, Contract 244159, SMASH-CIRED, France, 41 pp., 2011.

Raschky, P. A.: Institutions and the losses from natural disasters, Nat. Hazards Earth Syst. Sci., 8, 627-634, doi:10.5194/nhess-8627-2008, 2008.

Rasmussen, T. N.: Macroeconomic implications of natural disasters in the Caribbean, International Monetary Fund, 2004.

Rose, A. and Liao, S. Y.: Modeling regional economic resilience to disasters: A computable general equilibrium analysis of water service disruptions, J. Region. Sci., 45, 75-112, 2005.

Rose, A., Benavides, J., Chang, S. E., Szczesniak, P., and Lim, D.: The regional economic impact of an earthquake: Direct and indirect effects of electricity lifeline disruptions, J. Region. Sci., 37, 437-458, 1997.
Rose, A., Oladosu, G., and Liao, S. Y.: Business Interruption Impacts of a Terrorist Attack on the Electric Power System of Los Angeles: Customer Resilience to a Total Blackout, Risk Analys., 27, 513-531, 2007.

Strobl, E.: The economic growth impact of hurricanes: evidence from US coastal counties, IZA Discussion Papers 3619, 2008.

Tatano, H. and Tsuchiya, S.: A framework for economic loss estimation due to seismic transportation network disruption: A spatial computable general equilibrium approach, Nat. Hazards, 44, 253-265, 2008.

Tierney, K.: Business impacts of the northridge earthquake, J. Continencies Crisis Manage., 5, 87-97, 1997.

Tsuchiya, S., Tatano, H., and Okada, N.: Economic loss assessment due to railroad and highway disruptions, Economic Syst. Res., 19, 147-162, 2007.

Wu, J. D., Li, N., Hallegatte, S., Shi, P. J., Hu, A. J., and Liu, X. Q.: Regional indirect economic impact evaluation of the 2008 Wenchuan Earthquake, Environ. Earth Science, 65, 161-172, 2012.

Xie, W., Li, N., Hu, A. J., Gao, Y., and Ji, Z. H.: Assessing the economic impacts of environment disaster: a computable general equilibrium analysis, China Population, Resour. Environ., 11, 210-215, 2012 (in Chinese). 